Short Communication

\title{
Lack of mutations within ST7 gene in tumour-derived cell lines and primary epithelial tumours
}

\author{
VL Brown', CM Proby', DM Barnes² and DP Kelsell*,I \\ 'Centre for Cutaneous Research, Barts and The London, Queen Mary's School of Medicine and Dentistry, 2 Newark Street, Whitechapel, London EI 2AT, UK; \\ ${ }^{2}$ Hedley Atkins/Cancer Research UK Breast Pathology Laboratory, Guy's Hospital, Thomas Guy House, St. Thomas Street, London SEI 9RT, UK
}

Many strands of evidence point to an important tumour suppressor gene (TSG) on human chromosome $7 \mathrm{q} 31$. Frequent deletions within $7 \mathrm{q}$ in cytogenetic analyses and a high rate of loss of heterozygosity $(\mathrm{LOH})$ for $7 \mathrm{q}$ microsatellite DNA markers are both mechanisms commonly encountered in a wide variety of human tumour types (Zenklusen and Conti, 1996). In addition, functional complementation assays show that microcell fusion of an intact chromosome 7 into cancer cell lines with $\mathrm{LOH}$ at $7 \mathrm{q} 31$ inhibits tumorigenicity (Ogata et al, 1993; Zenklusen et al, 1994).

A number of candidate genes for the 7q31 TSG have been described including ST7 (suppression of tumorigenicity 7) formerly known as RAY1 and HELG (Vincent et al, 2000). Strong evidence to support ST7 as the key TSG at this locus has recently been reported by Zenklusen et al (2001). Using a prostate cancer-derived cell line they have shown that ST7 can suppress in vivo tumorigenicity. In addition they described protein-truncating mutations of ST7 in three out of eight cancer-derived cell lines (three out of seven breast cancer and none out of one prostate cancer) and in four out of 10 primary colon carcinomas. The mutations were seen in exon 3 (four cases), exon 5 (two cases) and exon 12 (once) from the 16 exons of ST7.
To explore this further, we have performed mutational analysis of ST7 exons 3, 5 and 12 in a variety of cell lines (cancerous and non-cancerous) and primary epithelial cancer tissues. Mutation analysis was carried out using denaturing high performance liquid chromatography (DHPLC), which is highly specific and sensitive for the detection of genetic mutations, including small deletions, insertions and point mutations (Xiao and Oefner, 2001).

\section{MATERIALS AND METHODS}

Intron-specific primers derived from ST7 cDNA (GenBank AY009152) aligned to genomic sequence were designed to encompass exons 3, 5 and 12 of ST7 (Table 1). These primers were then used to amplify the DNA from 34 primary breast cancers, 27 sporadic cutaneous squamous cell carcinomas (SCCs), 34 cancerderived cell lines and 27 non-cancerous cell lines (Table 2), by PCR.

Fifty nanograms of DNA were amplified in a $50 \mu \mathrm{l}$ reaction mixture that contained $200 \mu \mathrm{M}$ dNTPs, $1 \times \mathrm{NH}_{4}$ reaction buffer, $1 \mathrm{mM} \mathrm{MgCl} 2,20$ pmol primers and 0.5 units Taq polymerase (Bioline, London, UK). Cycling conditions for exons 3 and 5 were as follows: $95^{\circ} \mathrm{C}$ for $5 \mathrm{~min}$ followed by 35 cycles of $95^{\circ} \mathrm{C}$ for $30 \mathrm{~s}$,

Table I Primer sequences used in PCR reactions (shown in the $5^{\prime}$ to $3^{\prime}$ direction)

\begin{tabular}{lllc}
\hline Primer name & Forward sequence & Reverse sequence & PCR product size (bp) \\
\hline Exon 3 & GGCATGTGTACAGAAGTCG & AGGTTGTCAACTCCATGGGA & 372 \\
Exon 5 & TCAACGCCTCTGCAGCTT & CTCCCATTCAGAAGGATGTATG & 232 \\
Exon 12 & GTGTAGATGCTTCCGGGTTG & CTGTGGGGATTCCACAGACT & 197 \\
\hline
\end{tabular}

*Correspondence: Dr DP Kelsell; E-mail: kelsell@cancer.org.uk Received 20 February 2002; revised 19 March 2002; accepted 26 April 2002 
$55^{\circ} \mathrm{C}$ for $30 \mathrm{~s}$ and $72^{\circ} \mathrm{C}$ for $30 \mathrm{~s}$, and a $10 \mathrm{~min}$ final extension at $72^{\circ} \mathrm{C}$. Cycling conditions for exon 12 were identical except for an annealing temperature of $60^{\circ} \mathrm{C}$ instead of $55^{\circ} \mathrm{C}$.

Prior to DHPLC analysis, heteroduplex formation of the PCR products was carried out by heating for $5 \mathrm{~min}$ at $94^{\circ} \mathrm{C}$ followed by cooling to $40^{\circ} \mathrm{C}$ at a rate of $0.03^{\circ} \mathrm{C} \mathrm{s}^{-1}$. DHPLC was performed using the Transgenomic WAVE DNA fragment analysis system (Transgenomic, Crewe, UK). The original PCR products of any sample traces for which an aberrant DHPLC elution profile

Table 2 Details of Cell Lines

\begin{tabular}{lclc}
$\begin{array}{l}\text { Tumour-derived } \\
\text { cell }\end{array}$ & $\begin{array}{c}\text { Number } \\
\text { of } \\
\text { line }\end{array}$ & $\begin{array}{l}\text { Nomples } \\
\text { tumour-derived } \\
\text { cell lines }\end{array}$ & $\begin{array}{c}\text { Number } \\
\text { of } \\
\text { samples }\end{array}$ \\
\hline Breast & 4 & Colorectal line & 2 \\
Colon & 4 & Normal lymphoblast & 3 \\
Ovarian & 7 & Xeroderma Pigmentosa & 6 \\
Pancreatic & 4 & B-lymphoid line & 2 \\
Lung & 3 & GMo0637 clone & 5 \\
Prostate & 2 & Ovarian line & $\mid$ \\
Epidermoid carcinoma & 2 & T-lymphoblastoid line & $\mid$ \\
Bladder & $\mid$ & Liver line & $\mid$ \\
Endometrial & $\mid$ & Ataxia Telangiectasia & $\mid$ \\
Testicular & $\mid$ & Chromosomal aberrant line & $\mid$ \\
Hepatocellular & $\mid$ & Immunodeficient fibroblast & $\mid$ \\
Osteosarcoma & $\mid$ & Virus-transformed fibroblast & $\mid$ \\
Cervical & $\mid$ & Transformed line (not specified) & $\mid$ \\
Lymphoma & $\mid$ & Transformed primary kidney cells & $\mid$ \\
Epithelial tumour & $\mid$ & & \\
$\quad$ (unspecified) & & & \\
\hline
\end{tabular}

A

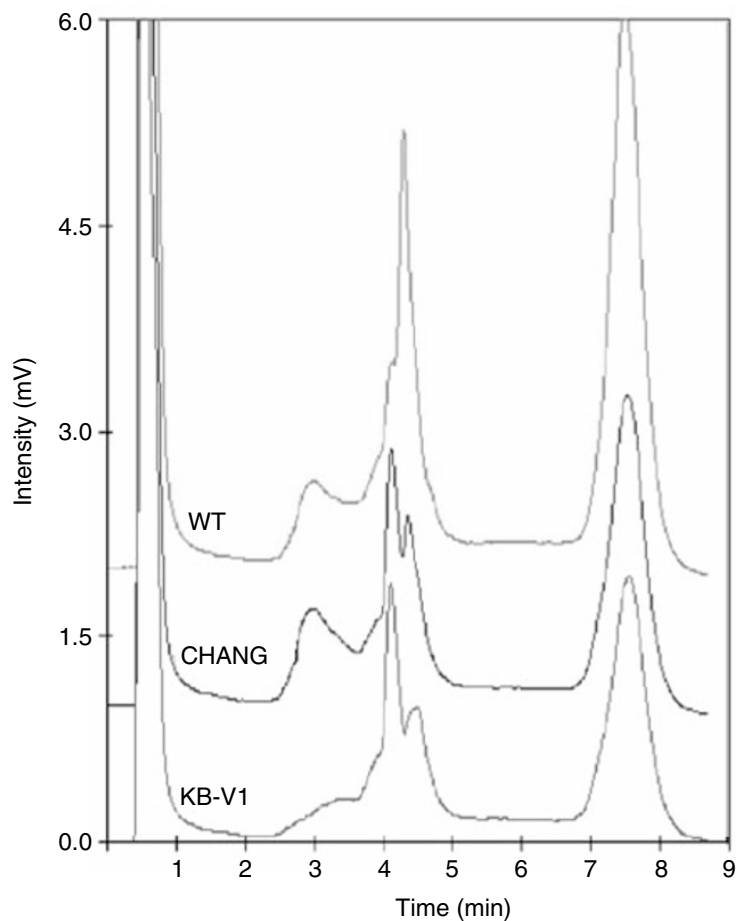

was observed, and all breast and colon cancer samples, were then sequenced directly. In addition, $10 \%$ of the samples with normal DHPLC elution profiles were sequenced. The PCR product was
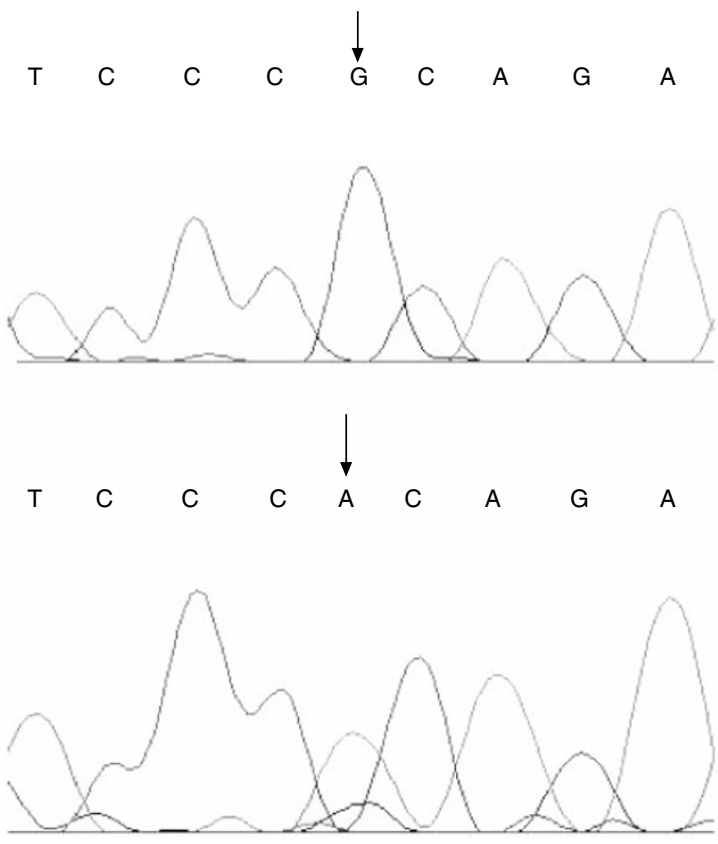

Figure I Sequence trace for MDA-MB435 breast cancer cell line (lower trace) showing a $\mathrm{G} \rightarrow \mathrm{A}$ substitution at codon 134 of ST7 compared to wild-type (upper trace).

B

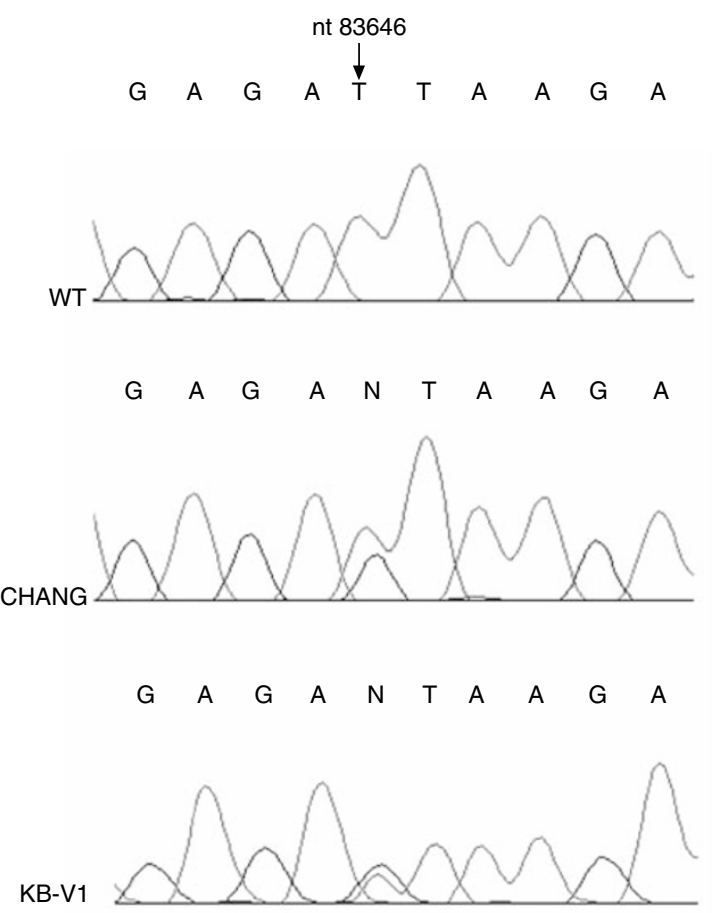

Figure 2 DHPLC and sequencing results of the ST7 intronic polymorphism. (A) DHPLC results showing variant traces for CHANG and KB-VI compared to the wild-type (WT) trace. (B) Sequencing showing ST7 intron 3 polymorphism in CHANG and KB-VI at nucleotide 83646, with reference to human BAC clone CTB-I| 4 A6. 
A

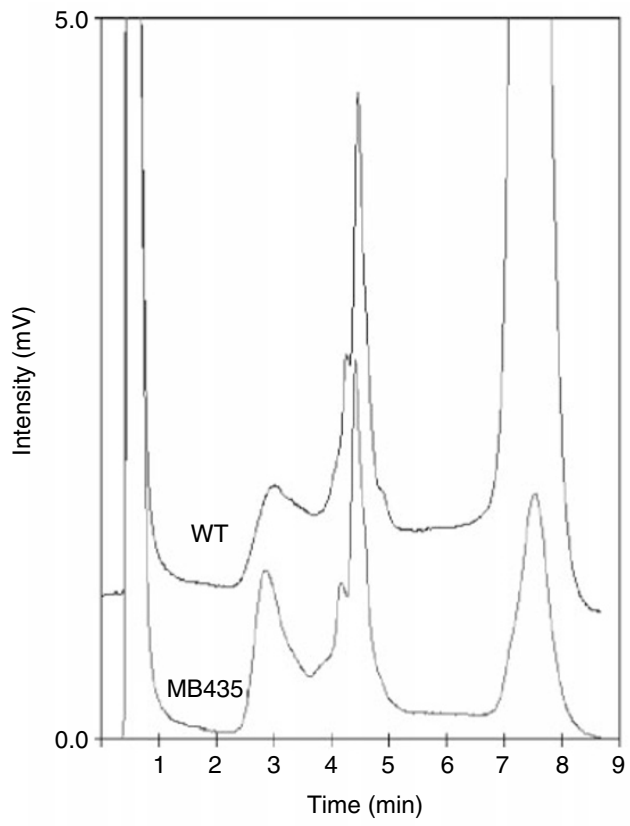

B

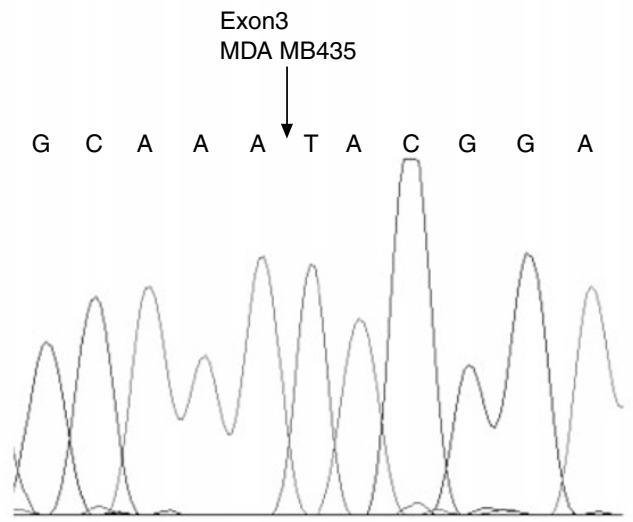

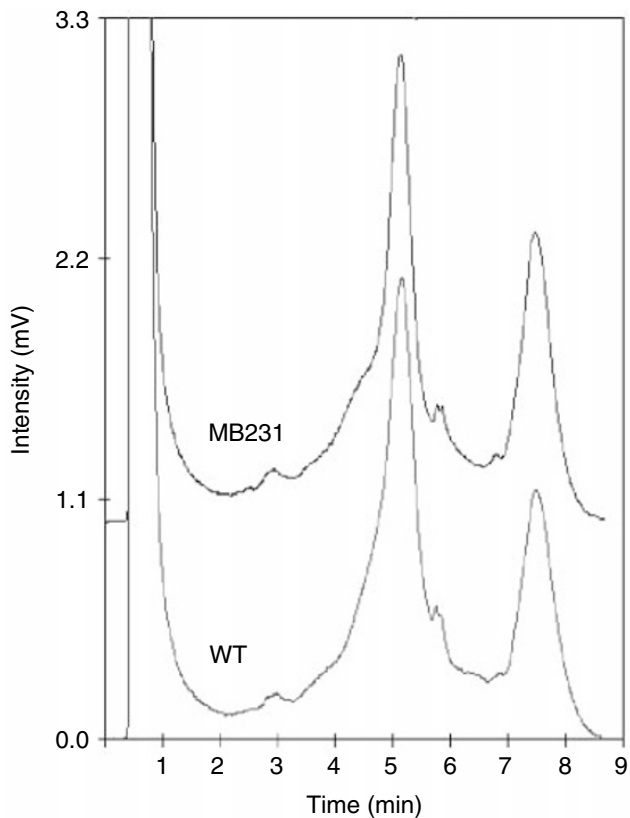

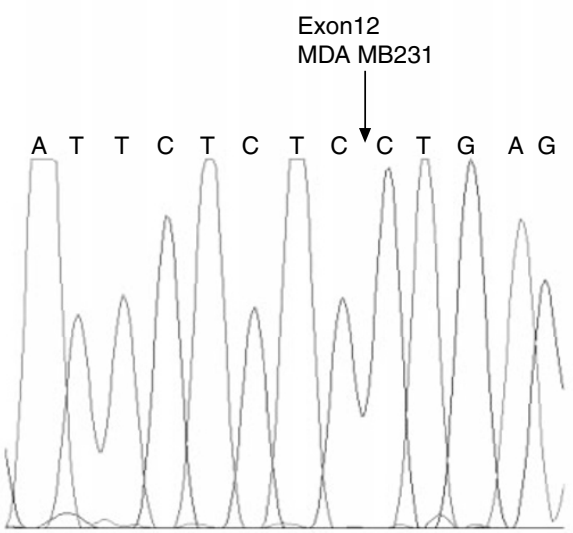

Figure 3 Wild-type profiles of DHPLC and direct sequencing for cell lines MDA-MB435 and MDA-MB23I. (A) DHPLC traces of ST7 exon 3 for MDAMB435 (left) and ST7 exon 12 for MDA-MB23I (right). Cell line traces are identical to wild-type (WT) in both cases. (B) ST7 sequencing of the cell lines MDA-MB435 (left) and MDA-MB23I (right) for exons 3 and 12 respectively. Arrows show site of mutations described by Zenklusen et al (200I) (466467ins T in MDA-MB435 and I 364- I 365insT in MDA-MB23 I), which are not seen in these traces. Nucleotides numbered according to GenBank AY009 I52 but note 4 bp discrepancy compared to Zenklusen et al (200I).

purified using a PCR purification column (Qiagen, Crawley, UK), and sequenced using Big-Dye terminator chemistry with the same primers as those used in the original PCR. Sequence analysis was conducted using an ABI 377 automated DNA sequencer and Sequence Navigator software (ABI, Warrington, UK).

\section{RESULTS AND DISCUSSION}

A single missense mutation in the breast cancer cell line MDAMD435 was detected in exon 5 of ST7 (Figure 1). This GCA $\rightarrow$ ACA substitution at codon 134 results in an Ala $\rightarrow \mathrm{Thr}$ amino-acid change. The functional consequence on the ST7 protein of this alteration is not known (Thomas et al, 2001). We also obtained variant DHPLC elution profiles for the epidermoid oral carcinoma line KB-V1 and liver cell line CHANG, in the exon 3 PCR products. The profiles from these two samples were similar to each other (Figure 2A) and subsequent sequencing revealed an identical $\mathrm{T} \rightarrow \mathrm{G}$ polymorphism in intron 3 (human BAC clone CTB-114A6; nucleotide 83646) in both cases (Figure 2B). We were unable to detect the single nucleotide insertions that Zenklusen et al (2001) reported in the breast cancer cell lines MDA-MB231 and MDAMB435 by either DHPLC (Figure 3A) or direct sequencing (Figure $3 \mathrm{~B}$ ). In addition none of the other truncating mutations previously described were found in any of the samples.

Mutational analysis in a wide-range of cell lines and primary epithelial tumours has shown that somatic alteration of ST7 rarely occurs in the exons examined. These results differ markedly from those recently reported (Zenklusen et al, 2001). This could be due to the fact that in the previous study all the tumours had been pre-screened for $\mathrm{LOH}$ at $7 \mathrm{q} 31$, thus increasing the likelihood of detecting a mutation. However, we found a high rate of $\mathrm{LOH}$ of $42 \%$ at $7 \mathrm{q} 31$ in breast tumours from our screening panel (using microsatellite markers D7S522 and D7S677 - data available on 
request) and would have expected to detect some mutations with this level of LOH. In addition, the cutaneous SCCs examined in this study displayed a lower but still significant rate of $\mathrm{LOH}$ at $7 \mathrm{q} 31$ of $22 \%$.

Other groups have recently found the same missense alteration in exon 5 in MDA-MB435 that we found (Hughes et al, 2001; Thomas et al, 2001). They also failed to detect any further coding mutations in all exons of ST7 in a wide-range of neoplastic carcinomas and cell lines, including ovarian, colon, breast, pancreatic and prostate. Our results extend the spectrum of histological types examined for ST7 somatic alterations.

In summary, genetic alteration by nucleotide mutation within ST7 is very rare in epithelial cancers and tumour cell lines. This suggests that if ST7 is the key TSG at $7 \mathrm{q} 31$, it is more likely to

\section{REFERENCES}

Hughes KA, Hurlstone AF, Tobias ES, McFarlane R, Black DM (2001) Absence of ST7 mutations in tumor-derived cell lines and tumors. Nat Genet 29: $380-381$

Ogata T, Ayusawa D, Namba M, Takahashi E, Oshimura M, Oishi M (1993) Chromosome 7 suppresses indefinite division of nontumorigenic immortalized human fibroblast cell lines KMST-6 and SUSM-1. Mol Cell Biol 13: $6036-6043$

Thomas NA, Choong DY, Jokubaitis VJ, Neville PJ, Campbell IG (2001) Mutation of the ST7 tumor suppressor gene on 7q31.1 is rare in breast, ovarian and colorectal cancers. Nat Genet 29: 379-380

Vincent JB, Herbrick JA, Gurling HM, Bolton PF, Roberts W, Scherer SW (2000) Identification of a novel gene on chromosome 7q31 that is interrupted by a translocation breakpoint in an autistic individual. $A m J$ Hum Genet 67: 510 - 514 be inactivated by epigenetic mechanisms or haplo-insufficiency than by direct mutation. Alternatively, one of the other TSG, or an undiscovered gene, at $7 \mathrm{q} 31$ is the target involved in carcinogenesis at this locus.

\section{ACKNOWLEDGEMENTS}

The authors would like to thank Research Cell Services and the Oligonucleotide Synthesis Group of Cancer Research UK for their valuable contribution to this study. VL Brown is a Medical Research Council Clinical Training Fellow.

Xiao W, Oefner PJ (2001) Denaturing high-performance liquid chromatography: A review. Hum Mutat 17: 439-474

Zenklusen JC, Conti CJ (1996) Cytogenetic, molecular and functional evidence for novel tumor suppressor genes on the long arm of human chromosome 7. Mol Carcinog 15: $167-175$

Zenklusen JC, Conti CJ, Green ED (2001) Mutational and functional analyses reveal that ST7 is a highly conserved tumor-suppressor gene on human chromosome 7q31. Nat Genet 27: $392-398$

Zenklusen JC, Oshimura M, Barrett JC, Conti CJ (1994) Inhibition of tumorigenicity of a murine squamous cell carcinoma (SCC) cell line by a putative tumor suppressor gene on human chromosome 7. Oncogene 9: 2817-2825 